\title{
Return Volatility and Asymmetric News Effect in Sri Lankan Stock Market
}

\author{
Sujeetha Jegajeevan ${ }^{\mathrm{a} /}$
}

Economic Research Department

Central Bank of Sri Lanka

\begin{abstract}
This paper studies daily and monthly returns in the Colombo Stock Exchange (CSE) in order to identify dynamics of return series and find out whether asymmetric volatility exists in the market. The study is carried out employing symmetric GARCH model, EGARCH model and GARCH-M model with a sample period from January 1998 to June 2009. It was found that daily return exhibits ARCH effect and it is not normally distributed. The monthly return series found to be normally distributed and it does not exhibit ARCH effect. In-depth analysis on daily return using symmetric GARCH model has supported the fact that the daily return shows time-varying volatility with high persistence and predictability. Asymmetric EGARCH model has found the presence of asymmetric volatility indicating that the market reacts more to a negative than shock a positive shock of the same size. It was also found that riskreturn relationship is not statistically significant, though it was found to be positive. These findings would be useful to policy makers, stock brokers and the investors in pricing, hedging and portfolio management and these models could be used to estimate and forecast volatility for risk management decision making at CSE.
\end{abstract}

a/ The author wishes to thank Mr. H.P.G.S. Ratnasiri for his valuable technical assistance throughout this study. 


\section{SECTION 1}

\section{INTRODUCTION}

Volatility in stock return is often perceived as a measure of risk, thus increasingly used in asset pricing, hedging, risk management and portfolio selection. Accurate modeling and forecasting of the variance receive a lot of attention in the investment community. Therefore, studying the stock market for identifying the persistence in volatility and its dynamics to the impact of news is worthwhile. Studies on this area generally focus on different properties of the return series such as volatility clustering, leptokurtosis and asymmetric news effect.

Though there are a number of studies on stock market volatility, studies focusing on emerging markets are very limited. A few studies have been carried out in South Asian regional stock markets, which have employed basic GARCH model and its variations to study the volatility and asymmetric news effects. This paper aims at studying the dynamics of stock return and conditional volatility in the Colombo Stock Exchange. The author attempts to find answers to the following questions:

- Does stock return volatility change over time?

- Does volatility persist for a long time?

- Is there an asymmetric volatility in stock return?, and

- What is the risk-return trade-off in the Sri Lankan Stock Market?

The study is carried out on the Colombo Stock Exchange with a sample period covering a long period of more than eleven years on daily basis starting from January 1998 to June 2009. All Share Price Index (ASPI) is studied for return volatility. In addition to the daily return, monthly return for the same sample period is also studied to examine whether daily returns and monthly returns show different properties. GARCH model is employed to determine the dynamics of the volatility series and EGARCH is applied for testing asymmetric news effect on volatility. Further, GARCH-M is used to study the relationship between expected risk and expected return.

This paper is organized as follows. Section 1 provides an overview of the research and Section 2 explains theoretical underpinnings and empirical evidences of the selected research area. Section 3 briefly describes the methodology. An in-depth analysis of the data is carried out in Section 4 followed by the conclusion in Section 5 . 


\section{SECTION 2}

\section{REVIEW OF LITERATURE}

\subsection{Introduction}

Return volatility is a measure of the intensity of unpredictable changes in asset returns. The task of volatility models is to explain the historical pattern of the volatility, estimate the parameters of the volatility and use these to forecast the volatility in the future. The majority of traditional economic models assume that the variance, as a measure of uncertainty, is constant over the time, while the empirical findings reject this. When the stock market is efficient the volatility in stock price should be related to the volatility in the variables affecting the stock price, mainly the dividend. However, empirical studies carried out in the past have proved that the volatility in dividend is not high as the volatility in stock prices. Thus, excessive volatility in stock prices is depended on the changes in discount rate also. Earlier researches on volatility assumed a constant discount rate. However since the discount rate is a measure of investors' preference for risk, which may change over time, the constant discount rate is therefore no longer valid. The research interest on stock market volatility thus have shifted from the dividend policies of corporate to investors' behavior and trading patterns in the market.

As noted by (Krainer, 2002) the volatility in stock return is not surprising: stock market volatility should depend on the overall performance of the economy and real economic variables themselves tend to display persistence in volatility. Volatility is a proxy for investment risk. Persistence in volatility implies that the risk and return tradeoff changes in a predictable way over the business cycle (Krainer, 2002). The persistence in volatility can be used to predict future economic variables in countries with advanced stock markets. For example, Campbell, Et. al. (2001) have shown that stock market volatility helps to predict GDP growth. Though, in countries like Sri Lanka, this might be unrealistic, because of relatively lower level of market capitalization to GDP. In Sri Lanka, though the market capitalization to GDP is relatively small compared to the advanced countries, the CSE is expanding and recording improved performance in the last few years. Therefore, though stock return volatility could not be considered as a predictor of economic performance in Sri Lanka, it provides some signal about the health of the financial markets and the economy. 


\subsection{Reasons for volatility}

While there is a general consensus on what constitutes stock market volatility, there is far less agreement on the causes of changes in the stock market volatility (Mala and Reddy, 2007). They further quote Engle and $\mathrm{Ng}$ (1991), who attribute arrival of new and unanticipated information as the key cause for the volatility. Some of the others attribute changes in trading volumes and pattern driven by the changes in macroeconomic policies, shift in investor tolerance of risk and increased uncertainty as a cause for volatility. In addition, political changes, civil security situation and global events are also cited as causes of return volatility. The volatility in the stock return is often explained based on the time span. Longterm volatility is mainly cased by financial leverage, operating leverage and state of the economy (Schwert, 1990). Returns on shares of highly leveraged firms are subject to more volatility, as the investors have to bear more risk. Similarly, operating leverage too has an impact on long term volatility of stock returns. Firms with a considerable amount of fixed costs are more vulnerable to changes in economic conditions. For instance, in the times of economic slowdowns, profits of those firms having more fixed costs tend to suffer more than the firms operating with limited fixed costs. Macroeconomic performance of the economy also has an impact on the long-term volatility. There are sufficient evidences to prove that the volatility increases during economic recessions. Great depression and the current financial crisis have records of high volatility in stock returns in stock exchanges all over the world.

In addition to the above factors there are certain factors which influence stock volatility in the short-term. Attempts by many people to trade simultaneously in the same direction (either to buy or sell) cause volatility in the market (Schwert, 1990). Arrival of a new piece of information (positive or negative) tends to make investors to think the current price is too low or too high. If all investors feel that the price is too high they will try to sell their share holdings immediately. When there is no corresponding buying interest from other investors, the prices will fall sharply, causing a short-term volatility in the returns.

Moreover, as noted by Schwert (1990) investor perception about the persistence of current movement in share prices will also influence the future movements of the share price. For example, once the price starts falling and the investors believe that the fall will continue, they will be willing to sell the shares. If there are no hunters of under-priced shares, it will end up with a sharp fall in prices. 


\subsection{Volatility Modeling}

Financial time series are found to depend on their own past value (autoregressive), past information (conditional) and exhibit non-constant variance (heteroskedasticity). Also, volatility in asset returns are found to be changing over time (time-varying) and exhibits positive serial correlations (volatility clustering) as cited by Bahadur (2008). Financial time series are said to have three main properties: volatility changes widely across the time (volatility clustering), leptokurtosis and leveraging effect. In the presence of these properties, employing constant variance models is inapt in financial time series. In most of the financial time series, variance of the error depends on the volatility of the errors in the recent past. Engle (1982) proposed Auto-Regressive Conditional Heteroskedasticity (ARCH) to deal with these situations. Empirical evidences suggest that high ARCH order has to be selected in order to capture the dynamics of the conditional variance. Bollerslev(1986) proposed a Generalised ARCH model (GARCH) for high order conditional variance. GARCH model as well as its variations has been employed by the majority of the researchers in this area.

There are mainly three reasons to model and forecast volatility. First, is to measure the risk of holding an asset (share). Second, is to obtain more accurate intervals by modeling the variance of the error, as forecast confidence intervals may be time-varying. Third, more efficient estimators can be obtained if heteroskedasticity in the errors is handled properly. ARCH models are specifically designed to model and forecast conditional variances. The term 'conditional' implies a dependence on the observations of the immediate past and the autoregressive and describes a feedback mechanism that incorporated past observations into the present. So that, ARCH and GARCH models are the mechanisms that included past variances and the past variance forecasts in the explanation and forecast of the future variances.

$\mathrm{ARCH}$ and GARCH models have become important tools in the analysis of time series data, especially the financial time series. The least square model, being the workhorse of applied econometrics was used to determine how much a variable will change in response to a change in other variables. However, when it comes to determine and forecast the size of the errors in a model, there should be some other tools. ARCH and GARCH are such tools to analysis and forecast the error (variability or volatility) in the models. The basic version of the lease square model assumes that the expected value of all the squared error terms (variance of error terms) is same at any given point. This property is known as homoskedasticity. But in general, there are some applications, in which the variance of error term is not equal and are expected to be large at some point or a range and small at some point or a range. This property is known as heteroskedasticity. In the presence of heteroskedasticity, the standard errors and the confidence intervals estimated conventionally by the least square model will be too narrow, though the regression coefficients are still unbiased 
(Engle, 2001). The ARCH and GARCH model treat heteroskedasticity as a variance to be modeled, instead of considering it as a problem to be corrected.

ARCH $(q)$ model was introduced by Engle (1982) assuming that the conditional variance depends on past volatility measured as a linear function of past squared values of the process. However, the linear ARCH model has certain shortcomings such as need for a long lag length $q$ and the non-negativity conditions imposed in parameters (Jorge, 2004). Bolleslev (1986) generalized the ARCH (GARCH $(p, q)$ ) process by allowing the conditional variance to be a function of prior period's squared errors as well as its past conditional variances. Following the introduction of ARCH and GARCH models there have been numerous refinements of the approach to modeling conditional volatility to better capture the stylized characteristics of the data (Bahadur, 2008).

However, though several merits are identified in favour of ARCH/ GARCH models, there are certain shortcomings of these models, which make these models inferior to ordinary ARMA/ ARIMA models in some cases.

Volatility clustering is one of the important properties generally observed in financial time series. It is known as a situation, where large changes in prices tend to be followed by large changes, whether it is positive or negative, and small changes tend to be followed by small changes. In the presence of volatility clustering, the squared series should be highly autocorrelated. A shock in volatility may affect the riskiness of investor portfolios not for days but also month after month (Jacobsen and Dannenburg, 2003). They highlight that volatility clustering, contrary to widespread belief, is not only present in high-frequency financial data. Monthly market returns also can exhibit significant serial dependence.

Engle, Lto and Lin (1990, cited in Karmakar 2007) provide two possible explanations for the presence of volatility clustering in return series. First, if information arrives in clusters, for instant information on interest rate, dividend, money supply, oil price etc, returns may exhibit clustering though the market incorporates the information perfectly and immediately. Secondly, if market participants take time to digest the information shocks and to resolve their expectation differences, market dynamics can lead to volatility clustering.

In many empirical researches it was found that volatility in the returns are highly persistent, for instance Franses and Dijk (1996), Kumar and Singhe (2008), Bahabur (2008), Karmakar (2007) etc. In many empirical applications using high frequency data with a long sample period one produce extreme persistence in the conditional variance, so that in the standard GARCH $(1,1)$ model the sum of $\mathrm{ARCH}(\alpha)$ and $\mathrm{GARCH}(\beta)$ parameters is close to one; i.e., $(\alpha+\beta \approx 1)$ (Jorge, 2004). This is due to the presence of an approximate unit root in the conditional variance. The situation of the sum of parameters of $\alpha$ and $\beta$ approaching unity is known as Integrated GARCH effect (IGARCH), which was proposed by Engle and Bollerslev. There are a number of studies focusing of IGARCH and validity 
of GARCH process with very strong persistence in volatility. IGARCH implies that the return series is not covariance stationary and multi-period forecast of volatility will trend upwards. Jensen and Lange (2007) argue that the estimation of GARCH $(1,1)$ models on financial returns almost always indicate that $\alpha$ is small and $\beta$ is close to unity and the sum of $\alpha$ and $\beta$ is very close to one and approaches one as the sample is increased. Following the works of Lamoreax and Lastrapes(1990, cited in Morana,2002), it is accepted in the literature that IGRACH effects can be spurious and due to unaccounted structural change in the return series.

Most of the studies on volatility of stock return also find that the variance of a stock is leptokurtic, which means that the distribution of the returns is fat-tailed (relative high probability for extreme values). This means that most of the time the stock moves around somewhat randomly. But when it deviates from this random pattern it runs a lot further and a lot faster than what market expects. So that, probability function will have fat tail.

Risk- return relationship is another property widely studied in the past. Before the introduction of ARCH models, the studies on risk-return tradeoff were based on the unconditional distribution of returns. Merton (1980, cited in Karmakar, 2007) criticized the failure of the previous studies account for the effect of changes in the level of risk when estimating expected returns. It is thus important to consider heteroskedasticity in using realized returns. GARCH-in-mean (GARCH-M) model allows conditional variance (risk) to affect the mean (expected return). The basic GARCH model is based on the implicit assumption that the average risk premium is constant for the sample period. The GARCH-M model relaxes this assumption by allowing the velocity feedback effect to become operational (Karmakar, 2007). The researches on risk-return relation have mixed results with both positive, negative or zero relation. For instance, for the US market, French et. al. (1987) and Campbell and Hentschel (1992) report a positive relation whereas Nelson (1991) and Glosten et. al. (1993) found a negative relationship. Baillie and DeGennaro (1990) and Chan et. al. (1992) report no significant relation. Poon and Taylor (1992) found that returns have a positive, though not statistically significant, relationship with expected volatility in the UK market. Balaban and Bayar (2005) have found mixed result on the relationship between market return and forecast volatility in a study of 14 countries.

Both ARCH and GARCH models captured the volatility clustering and leptokurtosis. However, GARCH models have restriction in handling asymmetric shocks to the volatility. An asymmetric response of conditional variance to positive and negative shocks in errors is known as leveraging effect. In other words, distribution of stock returns can be skewed to left if there are more negative observations and vice a versa. The leveraging effect occurs when an unexpected drop in price (bad news) increases predictable volatility more than an unexpected increase in price (good news). Thus, symmetric ARCH or GARCH models can not deal with such skewness and the result from these models can be spurious. 
The inability of GARCH models in capturing leveraging effect was discovered by Black (1976) and confirmed by French, Schwert and Stambaugh (1987), Schwert (1990) and Nelson (1991) and some other researchers. Several modifications were proposed by many academics to handle such asymmetric distributions. Nelson (1991) proposed an exponential GARCH (EGARCH) model, which is based on logarithmic expression of the conditional variability. Quadratic GARCH model (QGARCH) and Threshold ARCH (TARCH) are the other proposed models of this nature.

The leveraging effect is often illustrated graphically by a news impact curve. The new impact curve plots news scenarios (bad and good news) on the horizontal axis against the resulting volatility. This curve explains the different magnitude of the impact of good and bad news. Generally, the negative side of the curve is steeper than the positive side. A news impact curve for the stock return on an imaginary stock market is shown below.

Figure 2.1: News Impact Curve

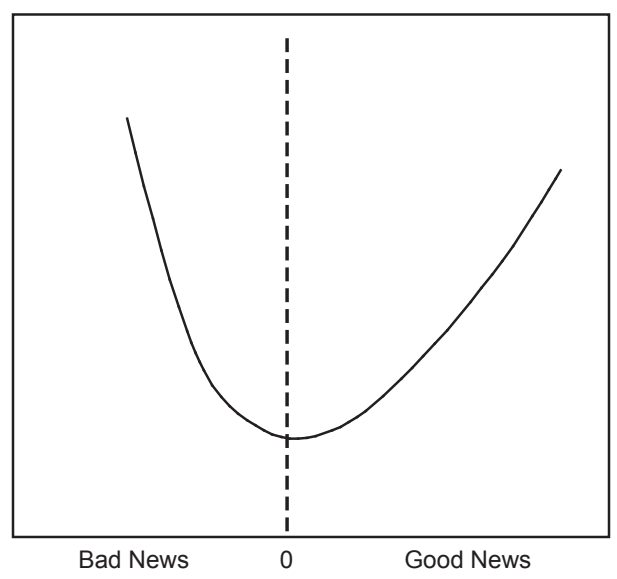

Though, there were a large number of studies on the dynamics of stock return volatility, the studies focusing on emerging market are very few. There were some studies on the Indian stock market, Nepalese market and Chinese market. The author could not find any study done in the past on Sri Lankan stock return volatility. Karmakar (2007), Roy and Karmakar (1995), Goyal (1995), Reddy (1997-98) Kaur (2002, 2004), Pandey (2005) and Bahadur (2008) are some studies carried out on South Asian stock markets in the past. The findings of most of these studies confirm that the return series in these markets conform to the stylized features of the return series in general. 


\section{SECTION 3}

\section{METHODOLOGY}

The study is carried out on the Colombo Stock Exchange with a sample period from January 1998 to June 2009. All Share Price Index (ASPI) is studied for return volatility. The daily data has been re-sampled to a 5-day week basis series (holidays during the weekdays are eliminated). The return is estimated as follows.

$$
r_{t}=\log \left(P_{t} / P_{t-1}\right)
$$

Thus logarithmic daily return at time $t$ is estimated by dividing the price index at time $t$ by the price index on previous day.

Symmetric GARCH $(1,1)$ model for daily stock is given below.

$$
\begin{aligned}
& r_{t}=a+b r_{t-1}+\varepsilon_{t} \\
& \sigma_{t}^{2}=\omega+\alpha_{1} \varepsilon_{t-1}^{2}+\beta_{1} \sigma_{t-1}^{2}
\end{aligned}
$$

The equation (1) is the mean equation and the equation (2) is the variance equation. The mean equation given in equation (1) is written as a function of previous day's return with an error term. Since $\sigma_{t}^{2}$ is the one-period ahead forecast variance based on past information, it is called the conditional variance. The conditional variance equation specified in (2) is a function of three terms:

(1) The mean: $\omega$

(2) News about volatility from the previous period, measured as the lag of the squared residual from the mean equation: $\varepsilon_{t-1}^{2}$ (the $\mathrm{ARCH}$ term)

(3) Last period's forecast variance: $\sigma_{t-1}^{2}$ (the GARCH term)

It should be noted that these estimations works only if the sum of ARCH term and GARCH term is less than unity $(\alpha+\beta<1)$ and the weights of the parameters are positive $\left(\alpha_{1}>0, \beta_{1}>0, \omega>0\right)$.

The $(1,1)$ in $\operatorname{GARCH}(1,1)$ is a standard notation in which the first number refers to how many autoregressive lags, or ARCH terms, appear in the equation, while the second number refers to how many moving average lags are specified (GARCH terms). Although this model is directly set up to forecast for just one period, it turns out that based on the 
one period forecast a two period forecast can be made and ultimately by repeating this step long horizon forecasts can be constructed (Engle, 2001). An ordinary ARCH model is a special case of a GARCH specification in which there are no lagged forecast variances in the conditional variance equation. The GARCH $(1,1)$ is the simplest and most robust of the family of volatility models. This model can be extended and modified in many ways. The GARCH $(1,1)$ can be generalized to a $\operatorname{GARCH}(p, q)$ model form for additional lag terms. In most applications, the simple GARCH $(1,1)$ model has been found to provide a good representation of a wide variety of volatility processes (Bollerslev, Chou and Kroner, 1992, cited in Jorge, 2004). However, high order models are useful to estimate the parameters efficiently when a long span of data is used.

EGARCH model is employed to test the asymmetric effect in the stock return. EGARCH model was originally developed by Nelson (1991). The EGARCH $(1,1)$ model is as follows. (only the variance equation is presented here, as the mean equation is same as in GARCH $(1,1)$ model).

$$
\log \sigma_{t}^{2}=\omega+\beta_{1} \log \sigma_{t-1}^{2}+\alpha_{1}\left|\varepsilon_{t-1} / \sigma_{t-1}\right| \gamma \varepsilon_{t-1}+\sigma_{t-1}
$$

In this equation, the conditional variance is expressed in the log form. The parameter $\gamma$ indicates the leverage effect. The exponential leverage effect is presented if $\gamma<0$ ( $\gamma$ is expected to be negative in real applications). The shock is asymmetric if $\gamma \neq 0$.

GARCH-M model is used to figure out the risk-return relationship. The application of this model relaxes the assumption held in the past, such as linearity, independence and constant conditional variance (Karmakar, 2007). The general GARCH (1,1)-M model is explained as follows.

$$
\begin{aligned}
& r_{t}=a+\delta \sigma_{t}^{2}+\varepsilon_{t} \\
& \sigma_{t}^{2}=\omega+\alpha_{1} \varepsilon_{t-1}^{2}+\beta_{1} \sigma_{t-1}^{2}
\end{aligned}
$$

The variable $a$ in the return equation can be considered as the risk free return in the CAPM and the $\delta \hat{\sigma}_{t}^{2}$ represents the market risk premium for the expected volatility. The risk-return trade-off parameter $\sigma$ can take a positive, a negative or zero value depending on the nature of the selected markets. There were empirical evidences for all these types of trade-off. In the GARCH-M framework, when $\sigma$ is statistically significant, then volatility $\left(\sigma_{t}^{2}\right)$ contributes to the risk premium and the premia may differ from times of relative instability to times of stability. 


\section{SECTION 4}

\section{EMPIRICAL ANALYSIS}

\subsection{Trend Analysis and Descriptive Statistics}

Before moving into in-depth econometric analyses it is more appropriate to carryout some fundamental statistical and historical trend analysis in order to better explain the properties of the selected data.

Table 4.1 and 4.2 give the 10 highest and 10 lowest daily and monthly returns, respectively, during the sample period. As noted, the highest positive returns of $20.1 \%$ and $25.3 \%$ have been recorded on daily and monthly basis, respectively, while the highest negative daily returns (lowest return) of $13.0 \%$ and $16.8 \%$, respectively, were recorded during the sample period. It is shown from the tables that monthly return is more volatile than daily return. Overall, there are some evidences of existence of return volatility in the Colombo Stock Exchange.

Table 4.1: 10 Highest and Lowest Daily Return

\begin{tabular}{lc|cc}
\hline \multicolumn{1}{c|}{ Highest } & & Lowest & \\
& $\%$ & & $\%$ \\
\hline 07-Dec-01 & 20.1 & 05-Nov-03 & $(13.0)$ \\
07-Nov-03 & 12.3 & 09-Feb-04 & $(10.5)$ \\
26-Jan-06 & 7.6 & 06-Apr-04 & $(9.5)$ \\
23-Mar-04 & 7.2 & 21-Nov-05 & $(7.3)$ \\
11-Oct-01 & 6.6 & 27-Dec-05 & $(7.1)$ \\
18-May-09 & 6.5 & 18-Nov-05 & $(6.9)$ \\
19-Nov-03 & 5.9 & 14-Nov-03 & $(6.8)$ \\
26-Jan-04 & 5.7 & 10-Nov-03 & $(6.2)$ \\
19-Jan-09 & 5.5 & 06-Dec-05 & $(6.0)$ \\
10-Dec-01 & 5.4 & 15-Jun-98 & $(5.2)$ \\
\hline
\end{tabular}

Table 4.2: 10 Highest and Lowest Monthly Return

\begin{tabular}{|c|c|c|c|}
\hline Highest & $\%$ & Lowest & $\%$ \\
\hline Oct-01 & 25.3 & Aug-98 & $(16.8)$ \\
\hline Jun-03 & 22.1 & Dec-05 & (16.2) \\
\hline Jan-09 & 21.2 & Oct-08 & (15.0) \\
\hline May-09 & 20.5 & Jun-98 & (14.9) \\
\hline Sep-03 & 19.4 & Nov-03 & (14.8) \\
\hline Dec-01 & 15.5 & May-98 & (12.7) \\
\hline Nov-98 & 15.3 & Nov-00 & (12.1) \\
\hline Jan-04 & 14.0 & Dec-03 & (12.0) \\
\hline Sep-02 & 13.9 & Sep-08 & (11.1) \\
\hline Sep-05 & 13.5 & May-07 & (10.8) \\
\hline
\end{tabular}

The summary statistics of logarithmic daily and monthly returns of ASPI is given in Table 4.3. The mean of both series are positive, indicating that overall the price indices have increased over the sample period. The return series shows a large gap between the maximum return and the minimum return. The standard deviation of monthly return is larger than the daily return, which confirms relatively high volatility in monthly returns. Statistics show 
Table 4.3: Descriptive Statistics of ASPI Return

\begin{tabular}{lcc}
\hline & Daily Return & Monthly Return \\
\hline Mean & 0.0005 & 0.0095 \\
Median & 0.0003 & 0.0077 \\
Maximum & 0.1829 & 0.2253 \\
Minimum & -0.1389 & -0.1842 \\
Std. Dev. & 0.0131 & 0.0768 \\
Skewness & 0.2996 & 0.0509 \\
Kurtosis & 30.6010 & 3.4950 \\
Jarque-Bera & $87,078.5$ & 1.4578 \\
Probability & 0.0000 & 0.4824 \\
\hline Q 2 (36) & 355.1900 & 34.2470 \\
& $(0.000)$ & $(0.552)$ \\
\hline Observations & 2,742 & 137 \\
\hline
\end{tabular}

that the returns are positively skewed, or in other words series have long right tails. This property is somewhat different from the properties observed generally in stock returns, which is a negative skewness. However, the positive skewness is relatively lower in the monthly return. Further daily returns are leptokurtic of fat tailed, given its large kurtosis. The Jarque-Bera test of daily returns rejects the null hypothesis of normality proving that the daily return series is not normally distributed. However, it accepts the normal distribution of monthly return, though the kurtosis value is slightly above 3 . Thus, the daily return series is not normally distributed, while the monthly return series is normally distributed.

\subsection{Volatility Clustering}

Statistically, volatility clustering implies a strong autocorrelation in squared returns. Large disturbances, positive or negative, become part of the information set used to construct the variance forecast of the next period's disturbances. The simple way to identify clustering is to calculate first-order autocorrelation coefficient in squared returns. If there is no serial correlation in the residuals, the autocorrelations (AC) and partial autocorrelations (PAC) at all lags should be nearly zero, and all $\mathrm{Q}^{2}$-statistics should be insignificant with large $p$-values. Ljung-Box Q squared statistic at lag 36 and its $p$-values are reported Table 4.3. The $\mathrm{Q}^{2}$-statistics at lag $k$ is a test statistic for the null hypothesis that there is no autocorrelation up to order $k$ (lag length). The $\mathrm{Q}^{2}$ (36) for daily return reveal the presence of 
Figure 4.1

Volatility Clustering of Daily and Monthly Returns on ASPI

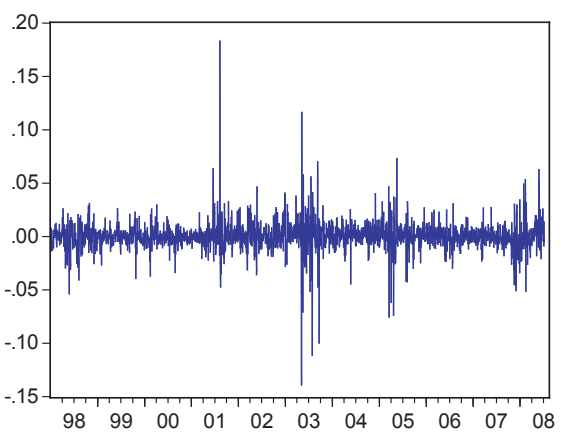

Daily Return on ASPI

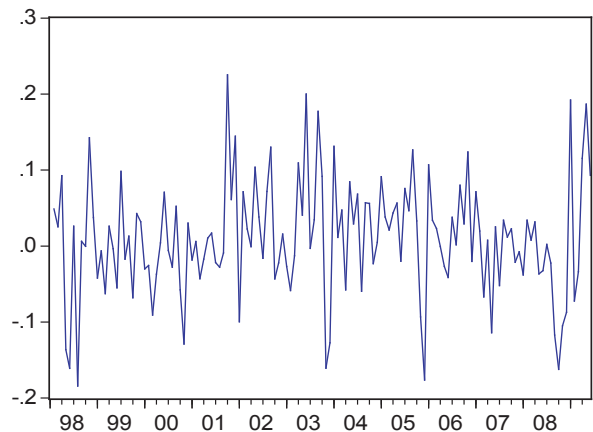

Monthly Return on ASPI

autocorrelation and hence volatility clustering in daily returns. The significance of autocorrelation coefficients gives evidence of ARCH effect in the daily return. However, the monthly return does not show evidence of clustering as the presence of autocorrelation and partial correlation is rejected. These characteristics are consistent with the characteristics of other financial time series. To conclude, the daily return series of ASPI is not normally distributed and exhibits 'ARCH effect', but monthly return is normally distributed and does not show 'ARCH effect'. Therefore, the GARCH analysis is carried out only on daily return.

The presence of volatility clustering in daily return is further confirmed by the plots of returns. The Figures 4.1 portrays the movements of daily and monthly returns on ASPI. Accordingly, it appears that in certain time period the volatility of daily return is relatively high and in certain periods the volatility is relatively low and the volatility is clustered together. However, such clustering is not observed in monthly return.

\subsection{Estimating Volatility Persistence using GARCH Model}

In a financial context, an investor predicts this period's variance by forming a weighted average of a long term average (the constant), information about volatility observed in the previous period (the $\mathrm{ARCH}$ term) and the forecasted variance from last period 
(the GARCH term). Symmetric GARCH $(1,1)$ model is employed to measure the nature of volatility persistence in daily returns.

In the GARCH model the size of the parameters of $\alpha$ and $\beta$ explains the dynamics of the volatility of the return series. Large GARCH error coefficient $\alpha$ means that volatility reacts very intensely to market movements and large GARCH lag coefficient $\beta$ means the shocks to conditional variance take a long time to die out or in other words volatility is persistent (Karmakar, 2007). If $\alpha+\beta$ is close to unity shock at time $t$ will persist for many future periods or volatility is persistent. In simple terms, it means that if there is any unexpected shock in the market, the resultant fluctuations will not die out immediately.

There are three basic assumptions of conditional error distribution in GARCH model: the Gaussian (normal) distribution, Student-t distribution and Generalized Error Distribution (GED). Though, the normal distribution is generally used in standard GARCH models, choosing appropriate assumption on the error distribution will give better result. Accordingly, in addition to the normal distribution the author tried the other two distribution assumptions also, such as Student-t and GED assumption. Based on the model selection criteria of minimum AIC value and maximum Log-L value, the student-t distribution is appeared to be more appropriate model.

Table 4.4 Garch Estimates for Daily Return on ASPI

\begin{tabular}{lcrrr}
\hline Estimates & GARCH (1,1) & GARCH $(2,1)$ & GARCH $(2,2)$ & \multicolumn{1}{c}{ GARCH (4,4) } \\
\hline$\alpha_{1}$ & $0.0000089(0.000)$ & $0.0000066(0.000)$ & $0.0000015(0.033)$ & $0.0000088(0.033)$ \\
$\alpha_{2}$ & $0.3669(0.000)$ & $0.4318(0.000)$ & $0.4301(0.000)$ & $0.4202(0.000)$ \\
$\alpha_{3}$ & - & $-0.1496(0.012)$ & $-0.3620(0.000)$ & $0.3858(0.000)$ \\
$\alpha_{4}$ & - & - & - & $-0.1474(0.023)$ \\
$\beta_{1}$ & - & - & - & $-0.2629(0.000)$ \\
$\beta_{2}$ & $0.6327(0.000)$ & $0.7165(0.000)$ & $1.3012(0.000)$ & $-0.2850(0.074)$ \\
$\beta_{3}$ & - & - & $-0.3704(0.000)$ & $0.5675(0.000)$ \\
$\beta_{4}$ & - & - & - & $0.3757(0.000)$ \\
Q ${ }^{2}(36)$ & - & - & - & $-0.0621(0.433)$ \\
Log-L & $20.44(0.983)$ & $19.04(0.99)$ & $17.94(0.995)$ & $16.09(0.998)$ \\
AIC & $9,069.2$ & $9,071.8$ & $9,076.2$ & $9,085.2$ \\
RMSE & -6.613 & -6.614 & -6.616 & -6.620 \\
MAE & 0.013054 & 0.013054 & 0.013054 & 0.013054 \\
MAPE & 0.007959 & 0.007959 & 0.007959 & 0.007959 \\
\hline
\end{tabular}

Note: Numers in parentheses are the probability values; Log-L - Log likelihood statistic; AIC - Akaike info criterion; RMSE - Root Mean Squared Error; MAE - Mean Absolute Error; MAPE - Mean Abs.Percent Error 
The result of the GARCH $(1,1)$ model, with Student-t assumption, is shown in the Table 4.4. According to the table the likelihood ratio statistic (Log-L) is large indicating the GARCH model is a suitable model representing the pattern of daily return series of ASPI, capturing temporal dependence of volatility( conditional volatility). The estimated GARCH lag coefficient $\beta_{1}(0.6327)$ is higher than the GARCH error coefficient $\alpha_{1}(0.3669)$ explaining that the long lasting persistence of volatility. In other words, the lag effect of volatility is stronger than new innovations. The summation of $\alpha$ and $\beta$ is close to unity (0.99), indicating a strong persistence of volatility or almost a permanent change in the volatility forecasting, which is very close to IGARCH property. If the volatility is highly persistent, then the volatility is predictable for the future period. High persistence of volatility (of around unity) was highly acceptable for high frequency data with longer period sample. This indicates that return series is not covariance stationary. It is suggested that either long memory or parameter changes in the data generating process can give the impression of this strong persistence (Jensen and Lange, 2007).

GARCH models with high orders were also tested to select the most suitable model, which captures the properties of the daily return of the Colombo Stock Exchange. Accordingly, the author tried various combinations of ARCH and GARCH lags and most appropriate 4 models are reported in the Table 4.4. With the model selection criteria of higher value of Log-l value and lower AIC value of the model as well as forecast result with lower values for RMSE, MAE and MAPE, the $\operatorname{GARCH}(4,4)$ model found to be the most appropriate model to describe the properties of daily return.

\subsection{Measuring the Asymmetric Volatility}

Since symmetric ARCH or GARCH models failed to address the asymmetric responses in the returns several modifications were proposed by many academics to handle such asymmetric distributions. Exponential GARCH (EGARCH), Quadratic GARCH model (QGARCH) and Threshold ARCH (TARCH) are some of the proposed models of this nature.

This paper has employed EGARCH models with different lag levels to study the asymmetric properties of the stock return. The result of the EGARCH $(1,1)$ and EGARCH $(2,1)$ models are shown in Table 4.5. Also the author tried the EGARCH $(2,2)$ and EGARCH $(4,4)$ models, but these models provided insignificant asymmetric coefficients. The value of $\gamma$ asymmetric coefficients are negative and significant at $95 \%$ confidence level. In other words, bad news tends to reduce the return more than the increase in return resulting from good news. Based on the findings of the models there is evidence 
Table 4.5: EGarch Estimates for Daily Return on ASPI

\begin{tabular}{lrr}
\hline Estimates & EGARCH $(\mathbf{1 , 1})$ & EGARCH $(\mathbf{2 , 1})$ \\
\hline$\omega$ & $-1.2575(0.000)$ & $-1.0702(0.000)$ \\
$\alpha_{1}$ & $0.5312(0.000)$ & $0.5908(0.000)$ \\
$\alpha_{2}$ & - & $-0.1126(0.000)$ \\
$\beta_{1}$ & $0.9049(0.000)$ & $0.9210(0.031)$ \\
$\gamma$ & $-0.0499(0.032)$ & $-0.0457(0.039)$ \\
$Q^{2}(36)$ & $17.12(0.99)$ & $16.45(0.99)$ \\
Log-L & $9,066.4$ & $9,068.5$ \\
AIC & -6.61 & -6.611 \\
RMSE & 0.013056 & 0.013056 \\
MAE & 0.00796 & 0.00796 \\
MAPE & 101.995 & 102.059 \\
\hline
\end{tabular}

Note: Numers in parentheses are the probability values; Log-L - Log likelihood statistic; AIC - Akaike info criterion; RMSE - Root Mean Squared Error; MAE - Mean Absolute Error; MAPE - Mean Abs.Percent Error.

of the presence of asymmetric volatility in daily returns. Based on the selection criteria of lower forecast errors EGARCH $(1,1)$ is found to be a better model, though EGARCH $(2,1)$ has a slightly higher value for Log-L.

\subsection{Estimating Risk-Return Trade-off}

GARCH-M model is employed to find out the risk-return relationship in daily returns. Empirical findings have examples of all types of relationship, such as positive, negative or zero, between expected risk and return. GARCH-M model with different lag levels have been tried to find out this relationship. All the models have found a positive, but not satistically significant relationship. It indicates that the expected return does not depend on the conditional variance. In other words, it shows the lack of risk-return trade-off over time. Karmakar (2007) and Jorge (2004) have found similar finding for Indian and Portuguese markets, respectively. Some papers suggest including asymmetric impact in the GARCH-M model to get a better result, i.e., EGARCH-M. The finding of the EGARCH $(2,1)$ model gives a better result among other asymmetric models. The result of the GARCH $(4,4)-\mathrm{M}$ model and EGARCH $(2,1)-\mathrm{M}$ model are presented in 
Table 4.6: Garch-M and EGARCH-M Estimates for Daily Return on ASPI

\begin{tabular}{|c|c|c|}
\hline Estimates & GARCH $(4,4)-M$ & EGARCH $(2,1)-M$ \\
\hline$\omega$ & $0.0000086(0.005)$ & $-1.0677(0.000)$ \\
\hline$\alpha_{1}$ & $0.4218(0.000)$ & $0.5907(0.000)$ \\
\hline$\alpha_{2}$ & $0.381(0.000)$ & $-0.1133(0.029)$ \\
\hline$\alpha_{3}$ & $-0.0 .1524(0.016)$ & - \\
\hline$\alpha_{4}$ & $-0.2625(0.000)$ & - \\
\hline$\beta_{1}$ & $-0.2701(0.094)$ & $0.9212(0.000)$ \\
\hline$\beta_{2}$ & $0.5619(0.000)$ & - \\
\hline$\beta_{3}$ & $0.3714(0.000)$ & - \\
\hline$\beta_{4}$ & $-0.0584(0.4575)$ & - \\
\hline$\gamma$ & - & $-0.0436(0.049)$ \\
\hline$\delta$ & $0.04854(0.265)$ & $0.01511(0.716)$ \\
\hline$Q^{2}(36)$ & $15.91(0.99)$ & $16.46(0.99)$ \\
\hline Log-L & 9,086 & $9,086.43$ \\
\hline AIC & -6.62 & -6.61 \\
\hline RMSE & 0.01313 & 0.01306 \\
\hline MAE & 0.0081 & 0.008 \\
\hline MAPE & 174.95 & 99.67 \\
\hline
\end{tabular}

Note: Numers in parentheses are the probability values; Log-L - Log likelihood statistic; AIC - Akaike info criterion;RMSE - Root Mean Squared Error; MAE - Mean Absolute Error; MAPE - Mean Abs.Percent Error

Table 4.6. Though, Log-L value and AIC value of the GARCH $(4,4)-\mathrm{M}$ model is better than EGARCH $(2,1)-M$ model, the forecast error in terms of MAPE has been largely reduced in the EGARCH $(2,1)-\mathrm{M}$ model along with small reduction in other forecast errors. Further, in the presence of asymmetric volatility in the daily return EGARCH-M models will be the most appropriate model. Thus, EGARCH $(2,1)-\mathrm{M}$ models has been chosen as the best model to explain the risk-return trade-off. 


\section{SECTION 5}

\section{CONCLUSION}

This paper has studied the daily and monthly returns on All Share Price Index of the Colombo Stock Exchange for a period of around eleven years starting from January 1998 to June 2009. The study is mainly focused on identifying persistence in volatility, risk-return trade-off and asymmetric volatility in return. Symmetric GARCH model along with its variations; EGARCH and GARCH-M, have been employed to estimate the volatility parameters.

It was found in the preliminary analysis that the daily return does not follow a normal distribution and shows signs of presence of ARCH effect in the return series, whereas the monthly return is confirmed to be normally distributed. Further, volatility clustering was observed in daily return, but not in the monthly return. Also, the daily return exhibits timevarying conditional heteroskedasticity and leptokurtosis. These finding are supported by empirical evidence of some other studies.

Symmetric GARCH model estimation confirms that $\mathrm{GARCH}(4,4)$ is more appropriate model than GARCH $(1,1)$ model. The estimated parameters show evidence of time-varying volatility exhibiting volatility clustering. High persistence in volatility and predictability was found in daily return.

Of the asymmetric models, EGARCH $(1,1)$ was found to be the most representative model. The leveraging effect was found in the daily returns, which indicates that the stock market becomes more volatile when negative shock takes place than the positive shock.

The risk-return trade-off analysis using GARCH-M and EGARCH-M model has found that EGARCH $(2,1)$-M model is preferred to other models. It shows a positive but insignificant risk-return relationship, indicating that there is no significant impact of conditional volatility on the expected return.

In overall, the daily return in the Colombo Stock Exchange exhibits most of the empirically proven stylized characteristics of the return, such as time varying volatility, high persistence and predictability and asymmetric volatility responses. But, there is lack of evidence for a significant risk-return trade-off. These findings would be useful since there has been no research done in the past on the Colombo Stock Exchange focusing on this area. Thus, the understanding about these properties would be helpful to policy makers and market participant in pricing the securities, deciding on the hedging strategy and portfolio management. Given the shortcomings of traditional volatility measurement techniques in capturing stylized features of stock return volatility, such as clustering, asymmetry etc., for 
the purpose of calculating the return volatility, these models could be experimented at the Colombo Stock Exchange (CSE) in estimating and forecasting the volatility in order to use them for risk management decisions.

In terms of limitations, complete applicability of these models to a small market like CSE might be questionable. It is because of two main reasons. Firstly, financial decisions are not solely based on expected returns or return volatility as assumed in ARCH / GARCH models. Global as well as domestic economic and political volatilities could be weighted more on the decision making than actual volatility in stock returns. Secondly, ARCH/ GARCH models are parametric estimates. They perform well under stable or perfect market situations. Such characteristic are lacking in Sri Lankan stock market. Thus, these models could not be completely substituted for the simple techniques like moving average, ARIMA etc. This study is an attempt to examine whether ARCH and GARCH models could be experimented in Sri Lankan stock market to identify persistence of volatility in stock return and stock return series exhibit well-known stylized features of financial time series. Thus, these models could be used to improve the current volatility estimation and forecasting. Future researches on this area could concentrate on using these models to forecast volatility and check for accuracy of forecasts. Also, comparative performance of traditional volatility estimation models and ARCH / GARCH models could be examined to recommend the best model to suit the characteristics of stock return at CSE. 


\section{REFERENCES}

1. Alberg D., Shalit H. and Yosef R. (2006), 'Estimating Stock Market Volatility Using Asymmetric GARCH Models', Monaster Center for Economic Research, Ben-Gurion University of the Neges, Israel, Discussion Paper No. 06-10.

2. Bahadur G.C.S. (2008), 'Volatility Analysis of Nepalese Stock Market', The Journal of Nepalese Business Studies, Vol. 5, 76-84.

3. Balaban E. and Bayar A. (2005), 'Stock Returns and Volatility: Empirical Evidence from Fourteen Countries', Applied Economics Letters, Vol. 12,603-611.

4. Batra A. (2004), 'Stock Return Volatility Patterns in India', Indian Council for Research on International Economic Relations, Working Paper No. 124.

5. Depken C.A. (2001), 'Good News, Bad News and GARCH Effects in Stock Return Data', Journal of Applied Economics, Vol. IV, 313-327.

6. Engle R.F. (2001), 'GARCH 101: An Introduction to the Use of ARCH/GARCH Models in Applied Econometric', NYU Working Paper No. FIN-01-030, Available at SSRN: http://ssrn.com/adstract=1294511.

7. Engle R.F. and Victor K. Ng (1991), 'Measuring and Testing the Impact of News on Volatility', NBER Working Paper Series, National Bureau of Economic Research, Cambridge, Working Paper No. 3681.

8. Franses P.H. and Dijk. D.V. (1996), 'Forecasting Stock Market Volatility Using (Non-Linear) GARCH Models', Journal of Forecasting, Vol. 15, 229-235.

9. Geng. J. (2006), 'Volatility Analysis for Chinese Stock Market using GARCH Model' Available at SSRN: http://ssrn.com/adstract=1020363.

10. Goonatilake R. and Herath S. (2007), 'The Volatility of the Stock Market and News', International Research Journal of Finance and Economics, Vol. 11.

11. Jacobsen B. and Dannenburg D.(2003), 'Volatility Clustering in Monthly Stock Returns', Journal of Empirical Finance, Vol. 10, 479-503.

12. Jensen A.T. and Lange T.(2007), 'Addressing the IGARCH Puzzle', University of Copenhagen, Unpublished.

13. Jorge C. (2004), 'Modeling and Forecasting the Volatility of the Portuguese Stock Index PSI-20', Portuguese Journal of Management Studies, No. 1 XI, 3-21. 
14. Karmakar M. (2007), 'Asymmetric Volatility and Risk-Return Relationship in the Indian Stock Market', South Asia Economic Journal, Vol. 8, 99-116.

15. Krainer J.(2002), 'Stock Market Volatility, FRBSF Economic Letter, No. 2002-32.

16. Kumar B. and Singhe P. (2008), 'Volatility Modeling, Seasonality and Risk-Return Relationship in GARCH-in-Mean Framework: The Case of Indian Stock and Commodity Markets', 5th Conference of Asia-Pacific Association of Derivative Paper, Available at SSRN: http://ssrn.com/adstract=1140264 .

17. Laakkonen H. and Lanne M. (2008), 'Asymmetric News Effects on Volatility: Good Vs, Bad News in Good Vs. Bad times', Helsinki Centre of Economic Research, University of Helsinki, Finland, Discussion Paper No. 207.

18. Magnus F.J. and Eric Fosu O.A. (2006), 'Modeling and Forecasting Volatility of Returns on the Ghana Stock Exchange Using GARCH Models , American Journal of Applied Sciences, Vol. 3, 2042-2048.

19. Mala R. and Reddy M. (2007), 'Measuring Stock Market Volatility in an Emerging Economy', International Research Journal of Finance and Economics, Euro Journals Publishing Inc, Issue 8.

20. Morana C. (2002), 'IGARCH effects: an interpretation', Applied Economic Letters, Vol. 9, 745-748.

21. Schwert G.W. (1988), 'Why Does Stock Market Volatility Change Over Time', NBER Working Paper Series, National Bureau of Economic Research, Cambridge, Working Paper No. 2798.

22. Schwert G.W. (1990), 'Stock Market Volatility', Financial Analysts Journal, Issue. May-June 1990, 23-34. 